\title{
Influence of Ramadan-type fasting on carbohydrate metabolism, brush border membrane enzymes and phosphate transport in rat kidney used as a model
}

\author{
Samina Salim, Neelam Farooq, Shubha Priyamvada, Mohammad Asghar, Syed Jalal Khundmiri, \\ Samia Khan, Farah Khan and Ahad Noor Khan Yusuf* \\ Department of Biochemistry, Faculty of Life Sciences, Aligarh Muslim University, Aligarh, 202002, UP, India \\ (Received 24 January 2007 - Revised 23 April 2007 - Accepted 24 April 2007)
}

Ramadan fasting is a unique model of fasting in which Muslims the world over abstain from food and water from dawn to sunset for 1 month. We hypothesized that this model of prolonged intermittent fasting would result in specific adaptive alterations in rat kidney to keep a positive balance of metabolites and inorganic phosphate $(\mathrm{Pi})$. The effect of Ramadan-type fasting was studied on enzymes of carbohydrate metabolism and brush border membrane (BBM) and BBM uptake of ${ }^{32} \mathrm{Pi}$ in different renal tissue zones in the rat model. Rats were fasted $(12 \mathrm{~h})$ and then re-fed $(12 \mathrm{~h})$ daily for $30 \mathrm{~d}$ similar to human Ramadan fasting. Ramadan-type fasting resulted in increased serum Pi and phospholipids, whereas Pi clearance decreased. Serum creatinine and its clearance were not affected. Fasting caused a significant decrease in the activities of lactate and malate dehydrogenases, glucose-6-phosphatase and fructose-1,6-bisphosphatase, both in the renal cortex and medulla. However, the activity of glucose-6-phosphate dehydrogenase profoundly increased but that of malic enzyme decreased. The activities of alkaline phosphatase and $\gamma$-glutamyl transpeptidase in BBM decreased, whereas transport of ${ }^{32} \mathrm{Pi}$ significantly increased. The decrease in enzyme activities and increase in ${ }^{32} \mathrm{Pi}$ transport were due to alterations of both maximal velocities and relative affinities. The results indicate that Ramadan-type fasting caused specific metabolic alterations with enhanced Pi conservation in different kidney tissues in a rat model used for Ramadan fasting in man.

Ramadan fasting: Carbohydrate metabolism: Kidney: Brush border membrane enzymes: Pi transport

Ramadan fasting (RF) is a unique model of prolonged intermittent fasting and re-feeding in which Muslims all over the world abstain from food and water from dawn to sunset for 29 or $30 \mathrm{~d}$ each year ${ }^{1,2,3}$. Eating and drinking is exclusively nocturnal during Ramadan. Fasting in general has been used in medicine for medical reasons including weight management. There are many adverse effects of total fasting as well as of crash diets. However, in RF there is no malnutrition or inadequate energy intake involved.

Kidneys play an essential role in the maintenance of total body fluid volume, its composition and $\mathrm{pH}$ by selective reabsorption. The major work of the kidney is $\mathrm{Na}^{+}$re-absorption. The transport of other solutes, e.g. sugars, amino acids and inorganic phosphate $(\mathrm{Pi})$ depends on $\mathrm{Na}^{+}$re-absorption ${ }^{4}$. $\mathrm{Na}$ serves both as a driving force, in terms of gradient $\left(\mathrm{Na}_{\text {extracellular }}>\mathrm{Na}_{\text {intracellular }} ; \mathrm{Na}_{\mathrm{o}}>\mathrm{Na}_{\mathrm{i}}\right)$ for translocation of solutes across brush border membrane (BBM) and as a factor modulating the interaction of Pi with Na-Pi co-transporter in the $\mathrm{BBM}^{4,5}$. The re-absorption functions of the kidney depend on the integrity of BBM and availability of energy in terms of ATP, provided by various metabolic pathways including glycolysis and oxidative metabolism ${ }^{5,6}$.

As millions of Muslims (young and old) have for centuries abstained from food and water in the daytime during the
Islamic month of Ramadan, it seems important to examine the influence of this fasting schedule on human health, especially with regard to renal metabolism and transport functions. It has been shown that RF in man increases total body fat oxidation whereas carbohydrate oxidation slows down ${ }^{7}$. However, we have recently shown that Ramadan-type fasting (RTF) caused a significant increase in the activities of various enzymes involved in carbohydrate metabolism both in the intestine and liver in the $\mathrm{rat}^{8}$. We now hypothesize that RTF would result in specific adaptive changes in renal metabolism and transport of Pi to maintain a positive balance of various metabolites and Pi for energy production.

To address this hypothesis, RTF was mimicked experimentally in rats used as a model for human RF. The rats were fasted $(12 \mathrm{~h})$ and then re-fed $(12 \mathrm{~h})$ daily for $30 \mathrm{~d}$. The influence of RTF was determined on enzymes of carbohydrate metabolism, BBM and on BBM uptake of ${ }^{32} \mathrm{Pi}$. Since the kidney is a heterogeneous structure consisting of several tissue zones, e.g. cortex and medulla, the effect of RTF was also examined in the homogenates and BBM prepared from different regions of the kidney. The results of the present study demonstrate that RTF caused variable alterations in metabolic activities but enhanced BBM transport capacity of ${ }^{32} \mathrm{Pi}$. 


\section{Materials and methods}

\section{Materials}

Wistar rats were purchased from All India Institute of Medical Sciences (New Delhi, India). ${ }^{32} \mathrm{Pi}$ was purchased from Bhabha Atomic Research Center, (Mumbai, India). Scintillation fluid (Cocktail-T) was purchased from Sisco Research Laboratory (Mumbai, India). All other chemicals used were of analytical grade and were purchased from Sigma Chemical Co. (St Louis, MO, USA) unless otherwise stated.

\section{Experimental design}

All animals were kept under conditions that prevented them from experiencing unnecessary pain and discomfort according to the guidelines approved by the Institution Ethical Committee. Adult male Wistar rats weighing 150-200 g, fed with a standard pellet diet (Amrut Laboratories, Pune, India) and water ad libitum, were conditioned for 1 week before the start of the experiment. Since rats are nocturnal feeders, the effect of RTF was initially determined on various renal enzymes and biochemical parameters in rats that were fasted for $12 \mathrm{~h}$ followed by $12 \mathrm{~h}$ re-feeding with either daytime or night-time feeding schedules for $30 \mathrm{~d}$ to rule out variations due to day or night food intake and a rhythmic pattern of certain enzymes as previously reported for intestinal studies ${ }^{8}$. The control rats received diet and water $a d$ libitum day and night, whereas food/water was available ad libitum to the fasted rats during re-feeding periods. It was noted that fasted rats rushed to eat and drink immediately when food/water was restored during the re-feeding period. The daily intake of food/water was carefully monitored and was found to be approximately the same for control and day/night-time fasted rats. The urine samples from control and experimental rats were collected for $4 \mathrm{~h}$ on the last day of fasting. The animals were killed following the last $12 \mathrm{~h}$ period of re-feeding. Blood was withdrawn, kidneys were extracted and cortex and medulla were separated and homogenates and BBM vesicles (BBMV) were prepared according to the method described later.

The results summarized in Tables 1 and 2 show that day/night RTF resulted in similar alterations of various parameters studied. As there was no significant difference between the respective controls, the values were pooled together to make one control value (see Results). These observations suggest that rats, whether fasted in the daytime or night-time, show similar adaptations as observed earlier ${ }^{8,9}$. Therefore, a comprehensive effect of RTF on BBM enzymes and Pi transport was determined as described later by daytime fasting $(12 \mathrm{~h})$ followed by a nighttime re-feeding ( $12 \mathrm{~h}$ ) schedule. After $30 \mathrm{~d}$ of the daytime fasting schedule, the rats were killed under light ether anaesthesia, kidneys were extracted and put in ice cold buffered saline for preparing homogenates and BBMV. The body weights (before and after the experiment) and kidney/cortex weights were recorded and are summarized in Table 3.

\section{Preparation of homogenates to determine enzymes of carbohydrate metabolism}

After completion of the fasting schedule, kidneys were removed, decapsulated and kept in ice cold buffered saline ( $154 \mathrm{mmol} / \mathrm{l} \mathrm{NaCl}, 5 \mathrm{mmol} / \mathrm{l}$ Tris-HCl, $\mathrm{pH} 7 \cdot 4)$. The cortex was carefully separated from medulla and a $15 \%(w / v)$
Table 1. Effect of daytime and night-time Ramadan-type fasting (Values are means with their standard errors for eight samples in each group) (A) Serum parameters

\begin{tabular}{|c|c|c|c|c|c|c|}
\hline \multirow[b]{2}{*}{ Group } & \multicolumn{2}{|c|}{$\begin{array}{l}\text { Creatinine } \\
(\mathrm{mg} / \mathrm{dl})\end{array}$} & \multicolumn{2}{|c|}{$\begin{array}{l}\text { Inorganic } \\
\text { phosphate } \\
(\mathrm{mmol} / \mathrm{ml})\end{array}$} & \multicolumn{2}{|c|}{$\begin{array}{l}\text { Phospholipid } \\
\quad(\mu \mathrm{g} / \mathrm{ml})\end{array}$} \\
\hline & Mean & SEM & Mean & SEM & Mean & SEM \\
\hline Control & 0.94 & 0.08 & $2 \cdot 19$ & 0.17 & $108 \cdot 75$ & 5.92 \\
\hline \multicolumn{7}{|c|}{ Ramadan-type fasting } \\
\hline Day & 1.00 & 0.01 & $3 \cdot 04^{*}$ & 0.23 & $223 \cdot 90^{*}$ & 2.92 \\
\hline & \multicolumn{2}{|c|}{$+6 \dagger$} & \multicolumn{2}{|c|}{$+39 \dagger$} & \multicolumn{2}{|c|}{$+106 \dagger$} \\
\hline Night & 1.02 & $0 \cdot 01$ & $+38 \dagger$ & $\begin{array}{r}0.02 \\
+\end{array}$ & \multicolumn{2}{|c|}{$+119 \dagger$} \\
\hline
\end{tabular}

(B) Urine parameters

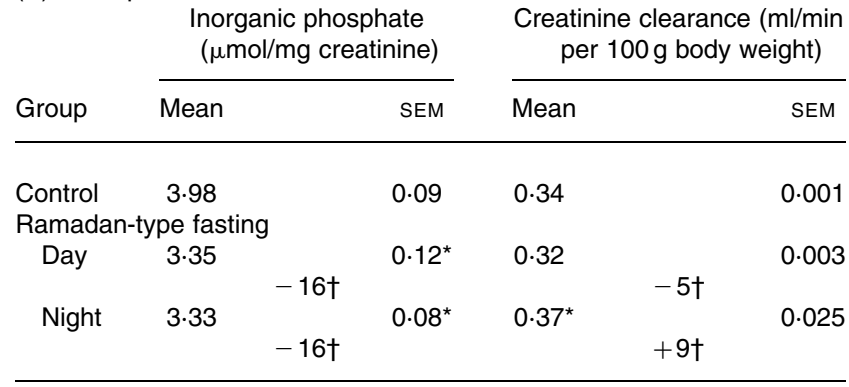

* Mean values were significantly different from control: $P<0.05$.

$\dagger$ Values represent percentage change from control values.

$\ddagger$ For details of procedures, see Materials and methods.

homogenate was prepared in ice cold $100 \mathrm{mmol} / \mathrm{l}$ Tris- $\mathrm{HCl}$, $\mathrm{pH} 7 \cdot 4$, using Potter-Elvehejem homogenizer (Remi motors, Mumbai, India) by passing five pulses ${ }^{10}$. The homogenate was centrifuged at $2000 \mathrm{~g}$ at $4^{\circ} \mathrm{C}$ for $10 \mathrm{~min}$ to remove cell debris and the supernatant fraction thus obtained was saved in aliquots and kept at $-20^{\circ} \mathrm{C}$ for enzyme analysis.

\section{Preparation of brush border membrane}

BBMV fractions were prepared at $4^{\circ} \mathrm{C}$ from homogenates of whole cortex, superficial cortex (BBMV-SC) and juxtamedullary cortex (BBMV-JMC) from the pool of the same kidneys simultaneously using $\mathrm{MgCl}_{2}$ precipitation techniques exactly as previously described 11 . Briefly, freshly minced tissues were homogenized in $50 \mathrm{mmol} / \mathrm{l}$ mannitol, $5 \mathrm{mmol} / \mathrm{l}$ TrisHEPES buffer, $\mathrm{pH} 7 \cdot 0$, in a glass Teflon homogenizer (Thomas, PA, USA) with five complete passes. The homogenate was then subjected to a high speed Ultra-Turrex Kunkel homogenizer (Type T-25; Janke \& Kunkel GMBH \& Co. $\mathrm{KG}$, Staufen, Germany) for three passes of $15 \mathrm{~s}$ each with an interval of $15 \mathrm{~s}$ between each pass. $\mathrm{MgCl}_{2}$ was added to the homogenate to a final concentration of $10 \mathrm{mmol} / \mathrm{l}$ and the mixture stirred for $20 \mathrm{~min}$ on ice. The homogenate was centrifuged at $2000 \mathrm{~g}$ in a Beckman centrifuge (J2 MI; Beckman Instruments Inc., Palo Alto, CA, USA) using a JA-17 rotor. The supernatant fraction was then centrifuged at $35000 \mathrm{~g}$ for $30 \mathrm{~min}$. The pellet was re-suspended in $300 \mathrm{mmol} / 1 \mathrm{mannitol}$, $5 \mathrm{mmol} / \mathrm{l}$ Tris-HEPES buffer, $\mathrm{pH} 7 \cdot 4$, with four passes by a loose fitting Dounce homogenizer (Wheaton, IL, USA) in a $15 \mathrm{ml}$ corex tube and centrifuged at $35000 \mathrm{~g}$ for $20 \mathrm{~min}$. The outer white fluffy pellet of BBM was re-suspended in buffered $300 \mathrm{mmol} / \mathrm{l}$ mannitol. Aliquots of homogenates (after high-speed homogenization) and BBMV thus prepared 
Table 2. Effect of a Ramadan-type fasting day on the specific activities of lactate dehydrogenase (LDH), malate dehydrogenase $(\mathrm{MDH})$, glucose-6-phosphatase (G6Pase), fructose-1,6- bisphosphatase (FBPase), glucose-6-phosphate dehydrogenase (G6PDH) and malic enzyme $(\mathrm{ME})$ in $(\mathrm{A})$ cortical homogenate $(\mathrm{CH})$ and $(\mathrm{B})$ medullary homogenate $(\mathrm{MH}) \ddagger$

(Values (specific activities: $\mu \mathrm{mol} / \mathrm{mg}$ protein per $\mathrm{h}$ ) are expressed as means with their standard errors for three different experiments)

\begin{tabular}{|c|c|c|c|c|c|c|c|c|c|c|c|c|}
\hline \multirow[b]{2}{*}{ Group } & \multicolumn{2}{|c|}{ LDH } & \multicolumn{2}{|c|}{$\mathrm{MDH}$} & \multicolumn{2}{|c|}{ G6Pase } & \multicolumn{2}{|c|}{ FBPase } & \multicolumn{2}{|c|}{ G6PDH } & \multicolumn{2}{|c|}{ ME } \\
\hline & Mean & SEM & Mean & SEM & Mean & SEM & Mean & SEM & Mean & SEM & Mean & SEM \\
\hline \multicolumn{13}{|l|}{ (A) $\mathrm{CH}$} \\
\hline Control & $17 \cdot 14$ & 0.61 & $86 \cdot 17$ & $0 \cdot 17$ & 1.87 & 0.04 & $4 \cdot 28$ & 0.15 & 1.25 & 0.25 & 1.03 & 0.11 \\
\hline \multicolumn{13}{|c|}{ Ramadan-type fasting } \\
\hline Day & $11 \cdot 69^{*}$ & 0.54 & $57 \cdot 03^{*}$ & 0.61 & 1.42 & 0.02 & 3.33 & 0.06 & $2 \cdot 88^{\star}$ & 0.61 & $0.37^{*}$ & 0.05 \\
\hline Night & $10 \cdot 30^{*}$ & 0.80 & $44.68^{*}$ & 0.88 & $1 \cdot 24^{-}$ & ${ }^{\dagger} 0.05$ & & 0.12 & $2.93^{*}$ & ${ }^{+} 0.77$ & & ${ }^{\dagger} 0.05$ \\
\hline (B) $\mathrm{MH}$ & \multicolumn{2}{|c|}{$-40 \dagger$} & \multicolumn{2}{|c|}{$-48 \dagger$} & \multicolumn{2}{|c|}{$-34 \dagger$} & \multicolumn{2}{|c|}{$-27 \dagger$} & \multicolumn{2}{|c|}{$+135 \dagger$} & \multicolumn{2}{|l|}{-7} \\
\hline Control & 24.08 & 0.44 & $52 \cdot 28$ & 0.07 & $1 \cdot 15$ & 0.02 & 3.51 & 0.10 & 0.58 & 0.09 & 0.69 & $0 \cdot 16$ \\
\hline \multicolumn{13}{|c|}{ Ramadan-type fasting } \\
\hline \multirow[t]{2}{*}{ Day } & $18 \cdot 82^{*}$ & 0.25 & $41 \cdot 01^{*}$ & 0.69 & 1.04 & 0.02 & $2 \cdot 85$ & 0.05 & $0.88^{*}$ & 0.06 & $0.37^{*}$ & 0.03 \\
\hline & \multicolumn{2}{|c|}{$-22 \dagger$} & \multicolumn{2}{|c|}{$-22 \dagger$} & \multicolumn{2}{|c|}{$-10 \dagger$} & \multicolumn{2}{|c|}{$-19 \dagger$} & \multicolumn{2}{|c|}{$+52 \dagger$} & \multicolumn{2}{|c|}{$-46 \dagger$} \\
\hline \multirow[t]{2}{*}{ Night } & $16 \cdot 31^{*}$ & 0.15 & $44 \cdot 72$ & 0.04 & 0.87 & 0.04 & $2 \cdot 77$ & 0.15 & $0.77^{\star}$ & 0.02 & $0.38^{*}$ & 0.06 \\
\hline & \multicolumn{2}{|c|}{$-32 \dagger$} & \multicolumn{2}{|c|}{$-14 \dagger$} & \multicolumn{2}{|c|}{$-24 \dagger$} & \multicolumn{2}{|c|}{$-21 \dagger$} & \multicolumn{2}{|c|}{$+33 \dagger$} & \multicolumn{2}{|c|}{$-45 \dagger$} \\
\hline
\end{tabular}

* Mean values were significantly different from control: $P<0.05$

$\dagger$ Values represent percentage change from control values.

$\ddagger$ For details of procedures, see Materials and methods.

were saved and stored at $-20^{\circ} \mathrm{C}$ until further analysis for BBM enzymes. Freshly prepared BBMV were used for Pi transport. In each experiment, tissues from three to five rats were pooled to obtain a sufficient amount of starting material.

\section{Enzyme assays}

The activities of marker enzymes in the homogenate and BBM fraction were determined by standard methods as described in a previous study ${ }^{11} . K_{\mathrm{m}}$ and $V_{\max }$ were determined by assaying these enzymes at various substrate concentrations, $0.6-$ $5.0 \mathrm{mmol} / \mathrm{l}$ for alkaline phosphatase (AlkPase), $0.1-0.6 \mathrm{mmol} / \mathrm{l}$ for $\gamma$-glutamyl transpeptidase (GGTase) and analysing the data by Lineweaver-Burk plot. Protein concentrations in BBMV preparations and homogenates were determined by the method of Lowry et al. ${ }^{12}$ as modified by Yusufi et al. ${ }^{13}$.

The activities of lactate dehydrogenase, malate dehydrogenase, glucose-6-phosphate dehydrogenase, malic enzyme involving oxidation of $\mathrm{NADH}$ or reduction of $\mathrm{NADP}^{+}$, were determined by measuring extinction changes at $340 \mathrm{~nm}$ in a spectrophotometer (Cintra 5; GBC Scientific Equipment Pty, Dandenong, Australia) as previously described ${ }^{8,10}$.

\section{Transport of ${ }^{32}$ inorganic phosphate}

Measurement of ${ }^{32} \mathrm{Pi}$ (Bhabha Atomic Research Center) uptake in BBMV was carried out at $25^{\circ} \mathrm{C}$ by rapid filtration technique as described by Yusufi et al. ${ }^{13,14}$ either in the presence or absence of Na-gradient. Uptake was initiated by addition of incubation medium $(30 \mu \mathrm{l})$ containing $100 \mathrm{mmol} /$ $1 \mathrm{mannitol}, \mathrm{NaCl} / \mathrm{KCl} 100 \mathrm{mmol} / \mathrm{l}, 5 \mathrm{mmol} / \mathrm{l}$ Tris-HEPES, $\mathrm{pH}$ 7.5, $\quad 0.1 \mathrm{mmol} / 1 \quad \mathrm{~K}_{2} \mathrm{H}^{32} \mathrm{PO}_{4}$ to $15 \mu \mathrm{l}$ BBM suspension (50-100 $\mu \mathrm{g}$ protein) and incubated for the desired time intervals (see Results). The uptake was stopped by the addition of $3 \mathrm{ml}$ ice cold stop solution (containing $135 \mathrm{mmol} / \mathrm{l} \mathrm{NaCl}$, $5 \mathrm{mmol} / \mathrm{l}$ Tris-HEPES and $10 \mathrm{mmol} / \mathrm{l}$ sodium arsenate, $\mathrm{pH}$ 7.5) and filtered immediately through $0.45 \mu \mathrm{m}$ DAWP Millipore filter, (Millipore Corporation, Billerica, MA, USA) and washed three times with the stop solution using a Cornwall type syringe (Wheaton, IL, USA). Correction for non-specific binding to filters was made by subtracting from all data the value of corresponding blank obtained by filtration of the incubation buffer without vesicles. The radioactivity of dried filters was measured by liquid scintillation counting (Reckbeta, LKB, Wallac, Sweden) with $10 \mathrm{ml}$ scintillation fluid (Cocktail T; Sisco Research Laboratory).

\section{Analysis of serum and urine parameters}

Serum and urine parameters were analysed by standard methods as previously described ${ }^{11}$.

Table 3. Effect of Ramadan type fasting on body weight, kidney weight and cortex weight of rats $\dagger$

(Values are means with their standard errors for three different experiments with four rats in each group for each experiment)

\begin{tabular}{|c|c|c|c|c|c|c|c|}
\hline \multirow[b]{2}{*}{ Group } & \multicolumn{2}{|c|}{ Body weight (g) } & \multicolumn{2}{|c|}{ Kidney weight (g) } & \multicolumn{2}{|c|}{ Cortex weight (g) } & \multirow[b]{2}{*}{ Kidney weight/ body weight } \\
\hline & Mean & SEM & Mean & SEM & Mean & SEM & \\
\hline Control & 213.33 & 8.34 & 1.36 & 0.046 & 0.66 & 0.00 & 0.0063 \\
\hline \multirow[t]{2}{*}{ Ramadan type fasting } & 185.08 & 4.33 & 1.23 & 0.03 & 0.62 & 0.012 & 0.0066 \\
\hline & \multicolumn{2}{|c|}{$-13^{*}$} & \multicolumn{2}{|c|}{$-10^{*}$} & \multicolumn{2}{|c|}{$-7^{\star}$} & \\
\hline
\end{tabular}

* Values represent percentage change from control values.

†For details of procedures, see Materials and methods. 


\section{Statistical analysis}

Results are expressed as means with their standard errors for at least three separate experiments. Each sample of BBM and homogenate was prepared by pooling tissues from four to five rats. The data are representative of twelve to fifteen rats per group per experiment. The data were analysed for statistical significance using Student's $t$ test for group and/or by one way ANOVA using SPSS 7.5 software (SPSS Inc., Chicago, IL, USA).

\section{Results}

Effect of day and night-time Ramadan-type fasting on serum and urinary parameters

As reported previously ${ }^{8}$, serum glucose, cholesterol and lactate dehydrogenase activity declined similarly by day or night-time RTF (data not shown). Serum creatinine and blood urea $\mathrm{N}$, two important parameters generally used to assess kidney functions, along with creatinine clearance were not affected by RTF. However, serum Pi and phospholipids both significantly increased (Table 1(A)) whereas Pi clearance was significantly lowered in RTF rats compared with control rats (Table 1(B)).

\section{Effect of day and night-time Ramadan-type fasting on enzymes} of carbohydrate metabolism in renal cortex and medulla

The effect of day/night-time RTF was determined on the activities of various enzymes involved in glucose degradation and/or its production in the homogenates of renal whole cortex and medulla. The activities of lactate dehydrogenase and malate dehydrogenase, representative enzymes of glycolysis and TCA cycle, respectively, significantly declined in cortical and medullary homogenates. The activities of glucose-6-phosphatase and fructose- 1,6-bisphosphatase, enzymes of gluconeogenesis, were also decreased similarly in RTF compared with control rats (Table 2). The activity of glucose-6-phosphate dehydrogenase (hexose monophosphate shunt) and malic enzyme, which play an important role in reducing anabolic pathways by producing NADPH, however, were differentially affected. The activity of glucose-6-phosphate dehydrogenase profoundly increased, whereas the activity of malic enzyme markedly decreased by RTF. RTF-induced changes in all the enzymes were always greater in cortical than in medullary homogenates. In addition, RTF caused a similar decrease in the activities of AlkPase and GGTase in BBMV isolated from whole cortex by the day/night fasting schedule (data not shown). The afore-mentioned results demonstrate that rats are suitable to study RF in man.

\section{Effect of daytime Ramadan-type fasting on the structure and transport functions of the kidney}

A major portion of various solutes, ions and water, are reabsorbed in the kidney by its proximal tubule across its $\mathrm{BBM}^{15}$. The BBM faces the lumen and contains a number of hydrolytic enzymes and transport systems ${ }^{16,17}$. The activities of these BBM enzymes and transport, in particular of ${ }^{32} \mathrm{Pi}$, have been shown to be affected by dietary $\mathrm{P}$ status, drugs and hormones 5 . In the present studies the effect of
RTF was examined on the activities of BBM enzymes, e.g. AlkPase and GGTase, and on the transport of ${ }^{32} \mathrm{Pi}$ in BBMV prepared from different cortical regions.

Effect of Ramadan-type fasting on body/kidney weight and brush border membrane marker enzymes. The body weight of rats in the RTF group was slightly lowered as compared with that of the control rats, a similar insignificant decrease in kidney and cortex weight was observed in the RTF group (Table 3). As shown in Table 4, the activities of AlkPase and GGTase in homogenates and BBMV isolated from whole cortex, BBMV-SC and BBMV-JMC declined by RTF. However, there was a greater decrease in BBMV than in the respective homogenates. Further analysis showed that AlkPase activity was profoundly lowered in BBMV-SC $(-37 \%)$, whereas the activity of GGTase preferentially decreased in BBMV-JMC $(-44 \%)$ after $30 \mathrm{~d}$ RTF. The kinetic parameters $\left(K_{\mathrm{m}}, V_{\mathrm{max}}\right)$ were also determined by assaying the enzymes in BBM preparations at different substrate concentrations. The results summarized in Table 5 show that RTF caused a decrease in $V_{\max }$ for AlkPase, whereas both $V_{\max }$ and apparent $K_{\mathrm{m}}$ values decreased for GGTase by RTF. While the reduction in $V_{\max }$ for AlkPase was largely observed in BBMV-SC, the decrease of both $V_{\max }$ and $K_{\mathrm{m}}$ values for GGTase was maximally observed in BBMV-JMC.

Effect of daytime Ramadan-type fasting on Na-gradient dependent transport of ${ }^{32}$ inorganic phosphate in brush border membrane vesicles isolated from whole, superficial and juxtamedullary cortices. The bulk of filtered $\mathrm{Pi}$ in the kidney is re-absorbed by its proximal tubule. In this nephron segment, the initial step in lumen to interstitial Pi transport involves secondary active $\mathrm{Na}$ gradient-dependent $\left(\mathrm{Na}_{\mathrm{o}}>\mathrm{Na}_{\mathrm{i}}\right)$ uptake of Pi across the BBM${ }^{4}$. The BBMV-SC and BBMV-JMC of rat kidney differ in their structure and transport properties ${ }^{13}$. The effect of RTF on uptake of ${ }^{32} \mathrm{Pi}$ was determined in the presence and absence of Na-gradient in the initial uphill phase $(10 \mathrm{~s}, 30 \mathrm{~s})$ and at equilibrium after $120 \mathrm{~min}$ in BBM preparations. The rate of concentrative uphill $(10 \mathrm{~s}, 30 \mathrm{~s})$ uptake of ${ }^{32} \mathrm{Pi}$ in the presence of Na-gradient $\left(\mathrm{Na}_{\mathrm{o}}>\mathrm{Na}_{\mathrm{i}}\right)$ was markedly increased in RTF compared with control values (Table 6). The concentrative uphill uptake $(30 \mathrm{~s})$ in relation to the equilibrium uptake $(120 \mathrm{~min})$, expressed as percentage overshoot $(\Delta \%)$, was also increased by $30 \mathrm{~d}$ RTF. However, the uptake of ${ }^{32} \mathrm{Pi}$ at the 'equilibrium' phase, at $120 \mathrm{~min}$ when $\mathrm{Na}_{\mathrm{o}}=\mathrm{Na}_{\mathrm{i}}$ was not significantly different between the two groups. Also Na-independent uptake (in the absence of a Na-gradient, $\mathrm{NaCl}$ in the medium replaced by $\mathrm{KCl}$, where $\mathrm{K}_{\mathrm{o}}>\mathrm{K}_{\mathrm{i}}$ ) of ${ }^{32} \mathrm{Pi}$ at $30 \mathrm{~s}$ and $120 \mathrm{~min}$ were also not affected by RTF, indicating specific alterations only when Na-gradient was present.

To localize the effect of RTF, the uptake of Pi was also determined in BBMV-SC and BBMV-JMC. As shown in Table 6, RTF caused a preferential increase of Na-gradient dependent uptake of ${ }^{32} \mathrm{Pi}$ in BBMV-SC compared with BBMV-JMC. The rate of $\mathrm{Pi}$ uptake was also determined with a wide range of $\mathrm{Pi}$ concentrations $(0 \cdot 05-1.0 \mathrm{mmol} / \mathrm{l})$. The kinetic parameters were determined graphically from double reciprocal plots of $\left(V_{\max }, K_{\mathrm{m}}\right)$ from the initial $(10 \mathrm{~s})$ ${ }^{32} \mathrm{Pi}$ uptake in the presence of $\mathrm{Na}$-gradient. RTF caused a marked increase of both apparent $V_{\max }$ and $K_{\mathrm{m}}$ values in various BBM preparations. However, RTF caused an increase of 
Table 4. Effect of Ramadan-type fasting on the specific activities of (A) alkaline phosphatase (AlkPase) and (B) $\gamma$-glutamyl transpeptidase (GGTase) in cortical homogenate $(\mathrm{CH})$ and brush border membrane vesicles (BBMV) from whole cortex (WC), superficial cortex (SC) and juxtamedullary cortex $(\mathrm{JMC}) \ddagger$

(Values (specific activities: $\mu \mathrm{mol} / \mathrm{mg}$ protein per $\mathrm{h}$ ) are expressed as means with their standard errors for three different experiments)

\begin{tabular}{|c|c|c|c|c|c|c|c|c|c|c|c|c|}
\hline \multirow{2}{*}{ Group } & \multicolumn{2}{|c|}{$\mathrm{WCH}$} & \multicolumn{2}{|c|}{ BBMV-WC } & \multicolumn{2}{|c|}{$\mathrm{SCH}$} & \multicolumn{2}{|c|}{ BBMV-SC } & \multicolumn{2}{|c|}{$\mathrm{JMCH}$} & \multicolumn{2}{|c|}{ BBMV-JMC } \\
\hline & Mean & SEM & Mean & SEM & Mean & SEM & Mean & SEM & Mean & SEM & Mean & SEM \\
\hline \multicolumn{13}{|l|}{ (A) AlkPase } \\
\hline Control & $35 \cdot 80$ & $1 \cdot 28$ & 248.84 & $19 \cdot 24$ & $15 \cdot 73$ & 0.12 & 163.84 & $2 \cdot 60$ & 13.96 & 1.90 & $106 \cdot 80$ & $2 \cdot 36$ \\
\hline \multirow[t]{2}{*}{ Ramadan-type fasting } & 35.28 & 1.44 & $188 \cdot 24^{\star}$ & 7.60 & 13.63 & 0.48 & $103.09^{*}$ & 0.72 & $12 \cdot 67$ & 1.73 & $91.50^{*}$ & 2.65 \\
\hline & \multicolumn{4}{|c|}{$-24 \dagger$} & \multicolumn{2}{|c|}{$-13 \dagger$} & \multicolumn{2}{|c|}{$-37 \dagger$} & \multicolumn{2}{|c|}{$-9 \dagger$} & \multicolumn{2}{|c|}{$-15 \dagger$} \\
\hline \multicolumn{13}{|l|}{ (B) GGTase } \\
\hline Control & 68.80 & 1.87 & $490 \cdot 20$ & $18 \cdot 10$ & 28.63 & 5.64 & 275.40 & $15 \cdot 55$ & 68.05 & $2 \cdot 34$ & 680.52 & 23.42 \\
\hline \multirow[t]{2}{*}{ Ramadan-type fasting } & 61.50 & 1.85 & $325 \cdot 10^{*}$ & 55.40 & $25 \cdot 27$ & 6.96 & $206 \cdot 25$ & 17.54 & 57.84 & 3.63 & $393.73^{*}$ & $25 \cdot 32$ \\
\hline & \multicolumn{2}{|c|}{$-11 \dagger$} & \multicolumn{2}{|c|}{$-34 \dagger$} & \multicolumn{2}{|c|}{$-12 \dagger$} & \multicolumn{2}{|c|}{$-25 \dagger$} & \multicolumn{2}{|c|}{$-15 \dagger$} & \multicolumn{2}{|c|}{$-42 \dagger$} \\
\hline
\end{tabular}

${ }^{*}$ Mean values were significantly different from control: $P<0.05$.

$\dagger$ Values represent percentage change from control values.

$\ddagger$ For details of procedures, see Materials and methods.

Table 5. Effect of Ramadan-type fasting on kinetic parameters of alkaline phosphatase (AlkPase) and $\gamma$-glutamyl transpeptidase (GGTase) in brush border membrane vesicles (BBMV) from whole cortex (WC), superficial cortex (SC) and juxtamedullary cortex (JMC)‡

\begin{tabular}{|c|c|c|c|c|c|c|}
\hline \multirow{2}{*}{ Group } & \multicolumn{2}{|c|}{ BBMV-WC } & \multicolumn{2}{|c|}{ BBMV-SC } & \multicolumn{2}{|c|}{ BBMV-JMC } \\
\hline & $V_{\max }^{*}$ & $K_{\mathrm{m}} \times 10^{-3} \mathrm{~mol} / \mathrm{l}$ & $V_{\max }^{*}$ & $K_{\mathrm{m}} \times 10^{-3} \mathrm{~mol} / \mathrm{l}$ & $V_{\max }^{*}$ & $K_{\mathrm{m}} \times 10^{-3} \mathrm{~mol} / \mathrm{l}$ \\
\hline \multicolumn{7}{|l|}{ AlkPase } \\
\hline Control & $222 \cdot 2$ & 1.05 & $152 \cdot 84$ & 0.76 & $100 \cdot 00$ & 0.58 \\
\hline Ramadan-type fasting & $142 \cdot 85$ & 0.83 & 86.95 & 0.62 & 74.07 & 0.54 \\
\hline & $-36 \dagger$ & $-21 \dagger$ & $-43 \dagger$ & $-18 \dagger$ & $-26 \dagger$ & $-7 \dagger$ \\
\hline \multicolumn{7}{|l|}{ GGTase } \\
\hline Control & 800 & $2 \cdot 50$ & 307.69 & $1 \cdot 11$ & 666.66 & 1.53 \\
\hline \multirow[t]{2}{*}{ Ramadan-type fasting } & 333.33 & 1.42 & 210.52 & 0.83 & 333.33 & 0.66 \\
\hline & $-58 \dagger$ & $-43 \dagger$ & $-32 \dagger$ & $-25 \dagger$ & -50 & $-57 \dagger$ \\
\hline
\end{tabular}

* $\mu \mathrm{mol} / \mathrm{mg}$ protein per $\mathrm{h}$.

† Values represent percent change from control values.

† For details of procedures, see Materials and methods.

both $V_{\max }$ and $K_{\mathrm{m}}$ to a much greater extent in BBMV-SC than in BBMV-JMC (Table 7).

\section{Discussion}

RF is a unique model of fasting in which Muslims the world over refrain from eating and drinking from dawn to sunset for $30 \mathrm{~d}$ each year and involves an unusual eating schedule. It has been established that an unusual eating schedule could induce different metabolic effects ${ }^{18}$. Previous human studies have reported that carbohydrate metabolism was slowed down by RF whereas fat oxidation significantly increased ${ }^{7}$. However, we recently observed that $\mathrm{RTF}$ in the rat model resulted in a profound increase in the activities of various enzymes involved in glycolysis, TCA cycle, gluconeogenesis and the hexose monophosphate shunt pathway in the intestine and liver ${ }^{8}$. Prolonged intermittent abstinence from water in addition to food for $12 \mathrm{~h}$ daily for $30 \mathrm{~d}$ may especially stress the kidney and alter its metabolic and transport functions.

We now hypothesize that RTF causes specific adaptive alterations in rat kidney to maintain a positive balance of various metabolites and $\mathrm{Pi}$ involved in energy production needed for various renal functions ${ }^{6,19}$. As reported earlier ${ }^{8}$, a $30 \mathrm{~d}$ $12 \mathrm{~h}$ fasting $/ 12 \mathrm{~h}$ feeding schedule in rats caused lowering of blood cholesterol and glucose with a slight decrease in body weight as observed after RF in human subjects ${ }^{1,2}$. Serum creatinine and blood urea $\mathrm{N}$ as well as creatinine clearance were not unaltered by $30 \mathrm{~d}$ RTF, suggesting that the body adapts well and that normal kidney functions remained intact. Although various changes in urine volume, osmolarity, solutes, ions $\left(\mathrm{Na}^{+}, \mathrm{K}^{+}\right)$and urea were observed after RF in human subjects, there were no apparent adverse effects on kidney functions ${ }^{3}$.

Prolonged intermittent RTF caused a significant decrease in lactate dehydrogenase and malate dehydrogenase activities in renal cortex and medulla. The activities of gluconeogenic enzymes, glucose-6-phosphatase and fructose-1,6-bisphosphatase were also decreased, suggesting that the enzymes involved in glucose degradation and its production were both decreased by a $30 \mathrm{~d} 12 \mathrm{~h}$ fasting/ $12 \mathrm{~h}$ feeding schedule in renal tissues. These observations in the kidney, however, were in contrast to the earlier observations on the influence of RTF on rat liver and intestinal carbohydrate metabolism, where RTF has resulted in increased activities of these enzymes ${ }^{8}$. The differential metabolic changes in different tissues can be attributed to differential adaptive mechanisms and/ or to the availability of metabolites to different tissues. It might be possible that soon after feeding, the metabolites were first utilized by the intestine and liver and fell short for renal metabolic activities. The renal levels of metabolites 
Table 6. Effect of Ramadan-type fasting on ${ }^{32}$ inorganic phosphate uptake in brush border membrane vesicles (BBMV) from whole cortex (WC), superficial cortex (SC) and juxtamedullary cortex (JMC)‡

(Values are means with their standard errors for three different experiments)

\begin{tabular}{|c|c|c|c|c|c|c|c|c|c|c|c|}
\hline \multirow{3}{*}{ Group } & \multicolumn{6}{|c|}{ Na-gradient dependent $\left(\mathrm{Na}_{\mathrm{o}}>\mathrm{Na}_{\mathrm{i}}\right)(\mathrm{pmol} / \mathrm{mg}$ protein) } & \multirow[b]{3}{*}{$\Delta \%$} & \multicolumn{4}{|c|}{ K-gradient dependent $\left(\mathrm{K}_{\mathrm{o}}>\mathrm{K}_{\mathrm{i}}\right)$} \\
\hline & \multicolumn{2}{|c|}{$10 \mathrm{~s}$} & \multicolumn{2}{|c|}{$30 \mathrm{~s}$} & \multicolumn{2}{|c|}{$120 \mathrm{~min}$} & & \multicolumn{2}{|c|}{$30 \mathrm{~s}$} & \multicolumn{2}{|c|}{$120 \mathrm{~min}$} \\
\hline & Mean & SEM & Mean & SEM & Mean & SEM & & Mean & SEM & Mean & SEM \\
\hline \multicolumn{12}{|l|}{ BBMV-WC } \\
\hline Control & $632 \cdot 02$ & $12 \cdot 52$ & $1430 \cdot 02$ & 5.74 & $169 \cdot 55$ & $15 \cdot 7$ & 746 & $130 \cdot 5$ & $25 \cdot 2$ & $153 \cdot 2$ & $27 \cdot 2$ \\
\hline Ramadan-type fasting & $962 \cdot 07^{\star}$ & $15 \cdot 24$ & $1926 \cdot 07^{*}$ & $18 \cdot 3$ & 166 & $5 \cdot 74$ & 1060 & 133.66 & 33.93 & $160 \cdot 97$ & $25 \cdot 7$ \\
\hline & \multicolumn{2}{|c|}{$+52 \dagger$} & \multicolumn{2}{|c|}{$+35 \dagger$} & & & $+42 \dagger$ & & & & \\
\hline \multicolumn{12}{|l|}{ BBMV-SC } \\
\hline Control & $821 \cdot 89$ & 19.67 & $1900 \cdot 21$ & 34.08 & 653.01 & $5 \cdot 35$ & 191 & 391.50 & $10 \cdot 55$ & 522.40 & 9.62 \\
\hline \multirow[t]{2}{*}{ Ramadan-type fasting } & $1126 \cdot 51^{*}$ & 18.94 & $2381 \cdot 16^{*}$ & $45 \cdot 2$ & $676 \cdot 13$ & $15 \cdot 28$ & 252 & $405 \cdot 00$ & $12 \cdot 35$ & $540 \cdot 80$ & $13 \cdot 94$ \\
\hline & \multicolumn{2}{|c|}{$+37 \dagger$} & \multicolumn{2}{|c|}{$+25 \dagger$} & & & $+32 \dagger$ & & & & \\
\hline \multicolumn{12}{|l|}{ BBMV-JMC } \\
\hline Control & 455.02 & $17 \cdot 19$ & 755.43 & $27 \cdot 34$ & 395.94 & 11.73 & 91 & $237 \cdot 20$ & $17 \cdot 19$ & $316 \cdot 00$ & $12 \cdot 37$ \\
\hline \multirow[t]{2}{*}{ Ramadan-type fasting } & $521 \cdot 14$ & 18.59 & $830 \cdot 20$ & $24 \cdot 26$ & 404.67 & 22.57 & 105 & $242 \cdot 70$ & 18.59 & 323.20 & $15 \cdot 07$ \\
\hline & \multicolumn{2}{|c|}{$+15 \dagger$} & \multicolumn{2}{|c|}{$+10 \dagger$} & & & $+15 \dagger$ & & & & \\
\hline
\end{tabular}

${ }^{*}$ Mean values were significantly different from control: $P<0.05$.

$\dagger$ Values in parentheses represent percent change from control values.

$\ddagger$ For details of procedures, see Materials and methods.

$\Delta \%$ overshoot at $30 \mathrm{~s}$ determined as a percentage change in uptake from $120 \mathrm{~min}$.

Table 7. Effect of Ramadan-type fasting on kinetic parameters of Na-dependent ${ }^{32}$ inorganic phosphate (Pi) uptake as a function of an external $\mathrm{Pi}$ concentration by brush border membrane vesicles (BBMV) from whole cortex (WC), superficial cortex (SC) and juxtamedullary cortex (JMC)‡

\begin{tabular}{|c|c|c|c|c|c|c|}
\hline \multirow{2}{*}{ Group } & \multicolumn{2}{|c|}{ BBMV-WC } & \multicolumn{2}{|c|}{ BBMV-SC } & \multicolumn{2}{|c|}{ BBMV-JMC } \\
\hline & $V_{\max }{ }^{*}$ & $K_{\mathrm{m}} \times 10^{-3} \mathrm{~mol} / \mathrm{l}$ & $V_{\max }^{*}$ & $K_{\mathrm{m}} \times 10^{-3} \mathrm{~mol} / \mathrm{l}$ & $V_{\max }{ }^{*}$ & $K_{\mathrm{m}} \times 10^{-3} \mathrm{~mol} / \mathrm{l}$ \\
\hline Control & $1250 \cdot 00$ & 0.087 & $1379 \cdot 31$ & 0.076 & 909.09 & 0.090 \\
\hline Ramadan-type fasting & $\begin{array}{c}2040 \cdot 81 \\
+63 \dagger\end{array}$ & $\begin{aligned} & 0.140 \\
+ & 61 \dagger\end{aligned}$ & $\begin{array}{c}2352 \cdot 94 \\
+71 \dagger\end{array}$ & $\begin{aligned} & 0.121 \\
+ & 59 \dagger\end{aligned}$ & $\begin{array}{l}1111 \cdot 11 \\
+22 \dagger\end{array}$ & $\begin{aligned} & 0.099 \\
+ & 10 \dagger\end{aligned}$ \\
\hline
\end{tabular}

${ }^{*} \mathrm{pmol} / \mathrm{mg}$ protein per $10 \mathrm{~s}$.

† Values represent percentage change from control values.

$\ddagger$ For details of procedures, see Materials and methods.

are considered to be in equilibrium with their levels in the blood, as blood is passed through the kidney multiple times during circulation, where various metabolites are re-absorbed. This can be supported by the fact that levels of blood glucose lactate and pyruvate fell during RF in human subjects ${ }^{1,2}$ resulting in the slowing down of the metabolism ${ }^{7}$.

In addition to metabolic enzymes, the activities of AlkPase and GGTase also declined significantly in BBM preparations by RTF. AlkPase activity sharply fell in BBMV-SC whereas the activity of GGTase preferentially decreased in BBMVJMC. The decrease in the activities of AlkPase and GGTase in the kidney was accompanied by the decrease of both $V_{\max }$ and $K_{\mathrm{m}}$ values, whereas in the intestine and liver the alterations were characterized by changes only in the $V_{\max }$ without any effect on $K_{\mathrm{m}}$ values $^{8}$. It has been established that AlkPase and GGTase are differentially located and organized in the thickness of $\mathrm{BBM}^{20}$; while AlkPase is considered to be a marker enzyme for BBMV-SC, GGTase is considered to be that of BBMV-JMC ${ }^{13}$. These enzymes appeared to be differentially altered by RTF due to their locations and organization in the BBM as was demonstrated by thyroid hormone and by low $\mathrm{Pi}^{21,22}$.
Renal handling of $\mathrm{Na}^{+}$and $\mathrm{Pi}$ is a critically important step in energy generation needed for many renal functions ${ }^{19}$. The bulk of filtered $\mathrm{Na}^{+}$and $\mathrm{Pi}$ are re-absorbed in the renal proximal tubule by active transport across its $\mathrm{BBM}^{4}$. The $\mathrm{Na}^{+}$-gradient $\left(\mathrm{Na}_{\mathrm{o}}>\mathrm{Na}_{\mathrm{i}}\right)$ dependent uptake of $\mathrm{Pi}$ by renal proximal tubular BBM is a rate limiting step and regulated by dietary $\mathrm{P}$ status, hormones and drugs ${ }^{19,21,22}$. The long-term phosphate deprivation in response to feeding a low-phosphate diet and the administration of thyroid hormones are the two experimental manoeuvres known to elicit the most pronounced long-term adaptive increases in the capacity of renal BBM for Na-gradient-energized $\mathrm{Na}$-Pi co-transport ${ }^{13,21}$. It has also been shown that BBMV-SC and BBMV-JMC differ in structure and in transport properties ${ }^{13,21}$.

RTF caused a significant increase in the uptake of ${ }^{32} \mathrm{Pi}$ by BBMV subpopulations. The increase in $\mathrm{BBM}$ uptake of ${ }^{32} \mathrm{Pi}$ was specifically observed in the presence of a Na-gradient $\left(\mathrm{Na}_{\mathrm{o}}>\mathrm{Na}_{\mathrm{i}}\right)$. RTF-induced adaptive increase in ${ }^{32} \mathrm{Pi}$ uptake was characterized by increase of both the maximal rate of the transport $\left(V_{\max }\right)$ and apparent $K_{\mathrm{m}}$. The increase in $V_{\max }$ of ${ }^{32} \mathrm{Pi}$ uptake can be considered as an increase in the number of newly synthesized transporters as demonstrated 
earlier $^{21,23,24}$ and the changes in $K_{\mathrm{m}}$ values may indicate changes in the intrinsic properties of the transporter. The increase in BBM uptake of Pi by RTF resulted in a parallel increase of serum $\mathrm{Pi}$ with a concomitant decrease of $\mathrm{Pi}$ excretion. The results are in partial agreement with the reported decrease of urinary excretion of both $\mathrm{Na}^{+}$and $\mathrm{Pi}$ in human subjects after $\mathrm{RF}^{3}$, suggesting an increase of both $\mathrm{Na}^{+}$and Pi re-absorption by the kidney. It has been shown that the decrease in $\mathrm{Na}^{+}$excretion persisted even 1 month after RF in human subjects ${ }^{3}$. It should be noted that decreased $\mathrm{Na}$ excretion could be the result of extra cellular volume contraction due to reduced water intake by an unknown mechanism ${ }^{3}$. The effect of RTF on ${ }^{32} \mathrm{Pi}$ transport seems similar to the effect of a low-Pi diet, where both the Pi transport and serum $\mathrm{Pi}$ increased in parallel ${ }^{22}$ and not like that of total fasting, where both Pi transport and serum Pi fell significantly ${ }^{25}$.

In summary, the results of the present study suggest that rats can indeed be used as a model for RF in man to study renal metabolism and transport of Pi. Prolonged, intermittent $30 \mathrm{~d}$ RTF caused specific adaptive changes in the metabolic activities and transport functions in the rat kidney. While metabolism appears to be slowed down, Na-gradient dependent uptake of ${ }^{32} \mathrm{Pi}$ was significantly enhanced, which maintains the positive balance of $\mathrm{Pi}$ needed for metabolic activities. Moreover, RTF seems to specifically affect the nephron subpopulations located in the superficial cortex. The results provide useful information of significant clinical importance on adaptations to unusual eating habits with restricted energy intake on renal metabolism and uptake of ${ }^{32} \mathrm{Pi}$.

\section{Acknowledgements}

This work was supported by a research grant (SO/SO/B-93/89) from DST to A.N.K.Y. The Council of Scientific and Industrial Research, New Delhi, India is acknowledged for the award of a Research Associate fellowship to N.F. S.J.K., M.A. and F.K. are recipients of a National Education Test fellowship from the University Grants Commission. Financial support to the department from University Grant Commission (UGC-DRF), Department of Science and Technology (DSTFIST) is also gratefully acknowledged.

\section{References}

1. Malhotra A, Scott PH, Scott J, Gee H \& Wharton BA (1989) Metabolic changes in Asian Muslim pregnant mothers observing the Ramadan fast in Britain. Br J Nutr 61, 663-672.

2. Nomani MZA, Hallack MH, Nomani S \& Siddiqui IP (1989) Changes in blood urea and glucose and their association with energy containing nutrients in men on hypocaloric diets during Ramadan fasting. Am J Clin Nutr 49, 1141-1145.

3. Cheah SH, Ch'ng SL, Husain R \& Duncan MT (1990) Effects of fasting during Ramadan on urinary excretion in Malaysian Muslims. Br J Nutr 63, 329-337.

4. Dousa TP \& Kempson SA (1982) Regulation of renal brush border membrane transport of phosphate. Miner Electrolyte Metab 7, 113-121.

5. Murer H \& Biber J (1996) Molecular mechanisms of renal apical Na/phosphate cotransport. Ann Rev Pysiol 58, 607-618.

6. Kurokawa K, Nagami GT \& Yamaguchi DT (1985) Transport and substrate metabolism of the kidney. In Renal Biochem
Cells, Membranes, Molecules 5, pp. 175-223 [RKH Kinne, editor]. Amsterdam, Oxford, New York: Elsevier Science.

7. El Ati J, Beji C \& Danguir J (1995) Increased fat oxidation during Ramadan fasting in healthy women: an adaptative mechanism for body weight maintenance. Am J Clin Nutr 62, 302-307.

8. Farooq N, Priyamvada S, Arivarasu NA, Salim S, Khan F \& Yusufi ANK (2006) Influence of Ramadan type fasting on enzymes of carbohydrate metabolism and brush border membrane in small intestine of rat used as a model. Br J Nutr 96, 1087-1094.

9. Saito M, Murakami E, Nishida Y, Fujisawa Y \& Suda M (1976) Circadian rhythms of digestive enzymes in the small intestine of rat. II Effects of fasting and refeeding. J Biochem (Tokyo) 80 , $563-568$.

10. Khundmiri SJ, Asghar M, Banday AA, Khan F, Salim S, Levi M \& Yusufi ANK (2004) Effect on ischemia and reperfusion on enzymes of carbohydrate metabolism in rat kidney. $J$ Nephrol 17, 377-383.

11. Khundmiri SJ, Asghar M, Khan F, Salim S \& Yusufi ANK (1997) Effect of reversible and irreversible ischemia on marker enzymes of BBM from renal cortical PT subpopulations. Am J Physiol 273, F849-F856.

12. Lowry OH, Rosebrough NJ, Farr AL \& Randall RJ (1951) Protein measurement with Folin phenol reagent. J Biol Chem 193, 265-275.

13. Yusufi ANK, Murayama N, Gapstur SM, Szczepanska-Konkel M \& Dousa TP (1994) Differential properties of brush border membrane vesicles from early and late proximal tubules of rat kidney. Biochim Biophysics Acta 1191, 117-132.

14. Khundmiri SJ, Asghar M, Banday A, Khan F, Salim S \& Yusufi ANK (2005) Effect of ischemia reperfusion on sodium-dependent phosphate transport in renal brush border membranes. Biochim Biophysics Acta 1716, 19-28.

15. Murer H, Werner A, Reshkin S, Waurin F \& Biber J (1991) Cellular mechanisms in proximal tubular reabsorption of inorganic phosphate. Am J Physiol 260, C885-C899.

16. Kenny AJ \& Booth AG (1976) Organization of the kidney proximal-tubule plasma membrane. Biochem Soc Trans 4, 1011-1017.

17. Murer H \& Biber J (1993) Structural identification of brush border membrane transport systems-towards an understanding of regulatory mechanisms. Clin Invest 71, 852-854.

18. Nelson W, Cadotte L \& Halberg F (1973) Circadian timing of single daily meal affects survival of mice. Pro Soc Exp Biol Med 144, 766-769.

19. Kempson SA \& Dousa TP (1986) Current concepts of regulation of phosphate transport in renal proximal tubules. Biochem Pharmacol 35, 721-726.

20. Guder WJ \& Ross BD (1984) Enzyme distribution along the nephron. Kidney Int 26, 101-111.

21. Yusufi ANK, Murayama N, Keller MJ \& Dousa TP (1985) Modulatory effect of thyroid hormones on uptake of phosphate and other solutes across luminal brush border membrane of kidney cortex. Endocrinology 116, 2438-2449.

22. Yusufi ANK, Murayama N, Szczepanska-Konkel M, Hoppe A \& Dousa TP (1989) Different mechanisms of adaptive increase in Na-Pi cotransport across renal brush border membrane. Am J Physiol 256, F852-F861.

23. Levi M (1990) Heterogeneity of Pi transport by BBM from superficial and juxtamedullary cortex of rat. Am J Physiol 258, 1616-1624.

24. Loghman-Adham M (1992) Mechanisms of heterogeneity of $\mathrm{Na}+-\mathrm{Pi}$ cotransport in superficial and juxtamedullary renal cortex. Biochim Biophys Acta 1105, 67-74.

25. Kempson SA, Shah SV, Werness PG, Berndt T, Lee PH, Smith LH, Knox FG \& Dousa TP (1980) Renal brush border membrane adaptation to phosphorus deprivation; effects of fasting compared to low phosphorus diet. Kidney Int 18, 36-47. 